Ana Grondona (compiladora),

Estilos de desarrollo

y buen vivir.

Ciudad Autónoma de Buenos Aires, Ediciones del CCC Centro Cultural

de la Cooperación Floreal Gorini, 2016, 212 páginas

ISBN 978-987-3920-19-6

\title{
Fernando Toyos*
}

Universidad de Buenos Aires

Centro de Estudios para el Cambio Social (CECS, Argentina).

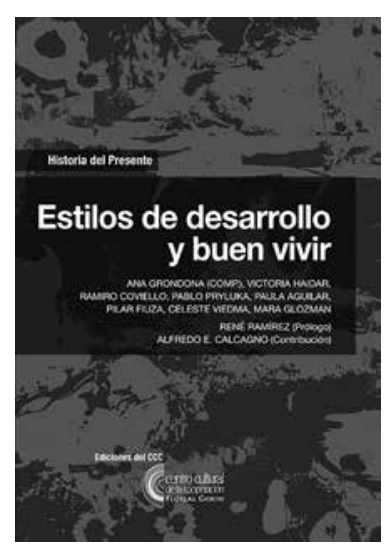

\section{INTRODUCCIÓN}

Tomo retrató Max Weber, en su clásico estudio sobre La ética protestante y el espíritu del capitalismo, Benjamin Franklin sintetizó la fórmula bajo la cual quedarían - ética y espíritu - unidos de allí en más: time is money, el tiempo es dinero. El kairós, el tiempo cualitativo concreto de la vida, convertido en chronos, tiempo abstracto y cuantitativamente mensurable. Tiempovalor de uso de la vida subsumido en el tiempo-valor de cambio de la producción y el consumo.

El desarrollo histórico del capitalismo ha pergeñado numerosas herramientas para medir la ratio de conversión entre uno y otro bien, desde el trabajo a destajo y los diversos incentivos por productividad (incluyendo, como sucedió recientemente en Argentina, la indexación de aumentos salariales a la evolución de la misma), incluyendo la cuantificación sistemática de los tiempos de trabajo sobre la que se construyó la organización taylorista del trabajo, como analiza Benjamin Coriat en El taller y el cronómetro.

* fertoyos.87@gmail.com 
Acaso la operación más ilustrativa de esta conversión de kairós en chronos la realizan los Estados nacionales cuando publican los índices de crecimiento económico, en especial el ampliamente aceptado Producto Bruto Interno (en adelante PBI) y su derivado, el PBI per cápita.

Estilos de desarrollo y buen vivir, compilado por la Dra. Ana Grondona es un aporte indispensable para polemizar con esta concepción de lo humano. Editado por el Centro Cultural de la Cooperación Floreal Gorini, ubicado en Buenos Aires, compila cinco artículos de investigadores/as del Grupo de Estudios sobre Historia y Discurso. A lo largo de sus páginas, las diferentes miradas convergen en la intención lograda de desestabilizar la noción hegemónica de desarrollo como única forma posible de entender el devenir económico y social de una comunidad.

\section{¿QUÉ DESARROLlO PARA QUÉ SOCIEDAD?}

En la década de 1970, América Latina fue escenario de un acalorado debate suscitado a partir de la publicación del informe del Club de Roma publicado bajo el nombre "Los límites del crecimiento" (Meadows, 1972). En este documento se planteaba, en el marco de un balance sobre la "primera década del desarrollo", la inminencia de una crisis del desarrollo producto de la incapacidad del Planeta Tierra de sustentarlo materialmente. Esta idea, con fuertes resonancias al planteo de Thomas Malthus, implicaba conclusiones similares: ante el límite físico-natural que el proceso de desarrollo está camino a encontrar, es necesario limitar el crecimiento de los países desarrollados y la natalidad de los países subdesarrollados. Estas ideas encontraron respuesta en nuestro continente, en especial a través de la Fundación Bariloche de Argentina y el Centro de Estudios del Desarrollo de Venezuela. Las investigaciones de dichos institutos llevarían a instalar una discusión sobre los estilos de desarrollo en plural, argumentando que los límites al crecimiento se relacionan con las pautas desmedidas de consumo, propias de los países del centro capitalista. De este modo, la idea-fuerza de estos trabajos gira en torno al carácter social de los límites del crecimiento. 
Más allá de este punto, lo que se pone sobre el tapete es la discusión sobre otros desarrollos posibles, más allá de la idea única que se esconde detrás de los indicadores económicos hegemónicos. En palabras de Oscar Varsavsky, se trata en todo caso de que "el país defina su estilo tecnológico propio, en base a su proyecto nacional, y con ese contexto crea, innova, innova, adapta e incluso compra si lo considera necesario" (Varsavsky, 2013 [1974]: 108, en Grondona, 2016: 27). De este modo, los indicadores sobre crecimiento y desarrollo solamente tienen sentido en el marco de un proyecto social, político y económico que los contenga. La discusión sobre los estilos de desarrollo llegaron incluso a reflejarse en el programa de gobierno de Juan Domingo Perón, en Argentina, para el mandato iniciado en 1973. Se trata del Plan Trienal de Reconstrucción y Liberación Nacional (en adelante PTRLN), el cual asociaba el "límite al crecimiento" con "un modelo de acumulación de capital basado en una regresiva distribución del ingreso" que se caracteriza por "patrones de comportamiento y aplicación de recursos de los sectores de ingresos elevados a costa de la satisfacción de las necesidades individuales y colectivas vitales" (PTRLN, 1973: 47, en Grondona, 2016: 25).

La definición de los estilos de desarrollo, junto con la historia polémica y de investigación que surgió alrededor de los mismos - historia que incluye la elaboración de sofisticados modelos de experimentación numérica - es relatada por uno de sus principales protagonistas, como investigador y redactor del PTRLN, Alfredo Eric Calcagno, en su contribución a la obra.

\section{BUEN VIVIR / VIVIR BIEN (SUMAK KAWSAY/SUMAK KAMAÑA)}

El cambio de siglo trajo consigo una serie de rebeliones populares en contra del neoliberalismo en toda la región, que cristalizó institucionalmente en el ascenso de una serie de gobiernos de carácter anti-neoliberal. Entre los más radicales de estos procesos - Bolivia, Ecuador y Venezuela - los dos primeros países avanzaron, además, en un cuestionamiento profundo a la lógica hegemónica del desarrollo, con sus rupturas y sus fuertes continuidades respecto 
a 1970, a partir de la idea del buen vivir/vivir bien. Este concepto es definido en el Plan Nacional para el Buen Vivir de Ecuador (en adelante, PNBVE) 2009-2013 de la siguiente manera, que conviene citar in extenso:

(Se entiende por "buen vivir") "La satisfacción de las necesidades, la consecución de una calidad de vida y muerte digna, el amar y ser amado, el florecimiento saludable de todos y todas, en paz y armonía con la naturaleza y la prolongación indefinida de las culturas humanas. El Buen Vivir supone tener tiempo libre para la contemplación y la emancipación, y que las libertades, oportunidades, capacidades y potencialidades reales de los individuos se amplíen y florezcan”.

(PNBVE 2009 - 2013, pág. 10).

La noción de buen vivir es desarrollada a lo largo de todo la obra, desde el prólogo de René Ramírez Gallegos, actual Secretario Nacional de Educación, Ciencia, Tecnología e Innovación del Ecuador, quien estuvo fuertemente involucrado en la redacción del PNBVE.

Estilos de DESARROLLO Y BUEN VIVIR, UN DiÁLOGO POSIBLE (Y NECESARIO)

Los múltiples diálogos posibles entre buen vivir y estilos de desarrollo son el hilo de plata que articula los distintos trabajos del libro que, desde miradas complementarias, convergen en la construcción de un puente a través del cual el buen vivir de hoy pueda nutrirse de las discusiones - en gran medida marginadas - sobre los estilos de desarrollo; reconociendo en ellas un antecedente a la vez que reconociéndose a sí misma como continuación - nuevamente: con sus continuidades y rupturas - de la anterior.

Tal el propósito del trabajo, corresponde a Ana Grondona, compiladora del libro y autora de su segundo capítulo, explorar los vínculos entre el debate por los estilos de desarrollo y la polémica contemporánea entre ciencia y "cientificismo", es decir, la disputa - siempre presente - por la construcción de conocimiento científicamente válido. Esta refriega tuvo como exponente destacado a Oscar Varsavsky, cuyos aportes - también descollantes en el campo 
de los estilos de desarrollo - son revalorizados en este apartado, junto con los del geólogo Amilcar Herrera, miembro de la Fundación Bariloche.

El buen vivir, traducción del quechua sumak kawsay, retoma elementos ancestrales de la tradición originaria, en la cual la figura de la pachamama - madre tierra - es central a la hora de entender la relación de los pueblos originarios con la naturaleza. Los vínculos entre el buen vivir, los estilos de desarrollo y la cuestión ecológica son analizados por Victoria Haidar en el capítulo III del presente volumen.

Como mencionamos anteriormente, la discusión sobre estilos de desarrollo señalaba que las causas - de orden social, político y cultural - relacionadas con "límite del crecimiento" se vinculaban a las pautas de consumo propias de los países del capitalismo central, e imitadas en nuestros países por las clases medias y altas. Las pautas de consumo pasadas y presentes, tanto de bienes de primera necesidad como de bienes de consumo suntuario, así como las alternativas que plantean los estilos de desarrollo y el buen vivir son abordadas por Ramiro Coviello y Pablo Pryluka en el cuarto apartado del tomo.

La subsunción del tiempo cualitativo, afectivo y concreto al tiempo cuantificable y desprendido de la materialidad afectiva y cotidiana es un proceso constitutivo del capitalismo actual, habiendo transformado las tradicionales concepciones circulares del tiempo (vinculadas a las estaciones del ańo, los tiempos de la cosecha y otros acontecimientos biológico-naturales) en la representación lineal de progresión infinita que conocemos actualmente. Esta primacía del chronos sobre el kairós, en el marco del modelo hegemónico de desarrollo, tiene efectos concretos sobre la forma de medir el crecimiento de una sociedad y sus habitantes. Paula Aguilar desarrollará una aguda crítica al respecto, planteando a su vez la(s) alternativa(s) posible(s) que pueden desprenderse de los estilos de desarrollo y el buen vivir, todo en el capítulo $\mathrm{V}$ de esta compilación.

El cierre de este importante trabajo corresponde a la contribución de Pilar Fiuza y Celeste Viedma, quienes insertaran las discusiones sobre estilos de desarrollo y buen vivir en el marco de las distintas 
estrategias de integración regional. Serán analizadas en este aporte tanto las discusiones en torno a la Asociación Latinoamericana de Libre Comercio, ALALC y sus contemporáneas, tanto como la nueva apuesta por la Patria Grande que nace en la Alternativa Bolivariana para los Pueblos de Nuestra América - Tratado de Comercio de los Pueblos (ALBA-TCP). Es de destacar que ambos proyectos de integración, pero especialmente el del ALBA, se proponen ir más allá de la mera integración de mercado, planteando proyectos ambiciosos como el Banco del Sur y el establecimiento de una moneda regional. El capítulo oficia también como cierre de esta obra, cuyo epílogo lo conforma un valioso anexo documental donde consultar trabajos de la Fundación Bariloche y Oscar Varsavsky. Quisiera, entonces, concluir esta reseña retomando las palabras del periodista y militante argentino Rodolfo Walsh - asesinado por la última dictadura militar de ese país - que resultan precisas para justipreciar la importancia de obras como Estilos de desarrollo y buen vivir. Espero esta reseńa haya hecho lo propio en incitar a explorar sus páginas con fruición.

"Nuestras clases dominantes han priocurado siempre que los trabajadores no tengan historia, no tengan doctrina, no tengan héroes ni mártires. Cada lucha debe empezar de nuevo, separada de las luchas anteriores, la experiencia colectiva se pierde, las lecciones se olvidan.

La historia parece asi como propiedad priada cuyos dueños son los dueños de todas las cosas. Esta vez es posible que se quiebre el círculo..."

\section{Fuentes:}

Plan Trienal para la Liberación y Reconstrucción Nacional (Argentina, 1973). Disponible online en: http://www.ruinasdigitales.com/ revistas/Plan\%20Trienal.pdf

Plan Nacional para el Buen Vivir del Ecuador, 2009-2013 (Ecuador, 2009). Disponible online en: http://www.buenvivir.gob. ec/versiones-plan-nacional\#tabs2 